\title{
RETÓRICAS Y ESTÉTICAS DEL DESCUBRIMIENTO DE AMÉRICA EN TAMBIÉN LA LLUVIA (2010), DE ICIAR BOLLAÍN
}

Núria LORENTE

Universidad de València

\section{RESUMEN}

En 2010 se estrena en España También la lluvia, una producción dirigida por Icíar Bollaín y escrita por Paul Laverty, sobre las circunstancias que atraviesan el rodaje de una película ambientada en el Descubrimiento de América. El escenario de grabación, la complicada Cochambamba del año 2000, y sus personajes, actores españoles y bolivianos, se verán envueltos a medida que se desarrolla el rodaje del film en un peligroso juego de semejanzas entre el conflicto social que viven y el acontecimiento histórico que filman.

Palabras clave: Descubrimiento, América, Cine, película, También la lluvia.

\section{ABSTRACT}

In 2010 it premieres in Spain "Also the Rain", a film by Icíar Bollaín about the circumstances that go through the filming of a film about the discovery of America. The recording stage, Cochabamba year 2000, and its actors, Spaniards and Bolivians will be involved, as the filming of the film develops, in a dangerous game of similarities between what they live and what they film.

Keywords: Discovery, America, cinema, film, También la lluvia.

\section{INTRODUCCIÓN}

La producción de contenidos culturales ambientados en el Descubrimiento del Nuevo Mundo ha hecho que la historia de la conquista de América ocupe un espacio importante en la industria cultural a lo largo del tiempo. La idea de América ha suscitado, desde el inaugural Diario de a bordo de Cristóbal Colón, diversas lecturas que han inspirado imaginarios sociales y dispositivos de representación en el ámbito artístico de diversa índole: Por una 
parte, la visión triunfal del Descubrimiento ha desencadenado una serie de representaciones culturales caracterizadas por una sintaxis gloriosa, totalmente descausalizada y consolatoria, que refuerza la hazaña heroica y casi mítica de la llegada de los españoles a América. Por otra, una perspectiva de estudio que escapa de la historiografía tradicional, que rescata a la memoria de los efectos sedantes del discurso del éxito y que genera una serie de dispositivos cuya representación problematiza, en sí misma, las versiones dominantes de la historia de la Conquista.

También la lluvia, película española, dirigida por Icíar Bollaín en 2010, forma parte de estos productos culturales que cuestionan el relato histórico operante. A partir del lenguaje visual y el tratamiento que se hace de los guiones de los personajes, el film formula una lectura que actualiza y resignifica la historiografía de la Conquista y que plantea la posibilidad de integrar el pasado y el presente para lograr una compresión más completa de lo que supuso el proceso de occidentalización y sometimiento del Nuevo mundo. El espectador de Bollaín se encuentra entonces en una tensión permanente entre el relato que se graba y el conflicto que se vive, lo cual no altera en ningún momento el desarrollo del argumento principal que, exceptuando los llamativos cambios de vestuario de los personajes, concatena, casi de forma imperceptible para el público, las diversas tramas hasta hacerlas converger en un punto común: el control del otro por el poder externo.

\section{LA PELÍCULA}

Articular históricamente el pasado no significa conocerlo como verdaderamente ha sido. Consiste, más bien, en adueñarse de un recuerdo tal y como brilla en el instante de un peligro. Al materialismo histórico le incumbe fijar una imagen del pasado, imagen que se presenta sin avisar al sujeto histórico en el instante de peligro. El peligro amenaza tanto a la existencia de la tradición como a quienes la reciben. Para ella y para ellos el peligro es el mismo: prestarse a ser instrumentos de la clase dominante. En cada época hay que esforzarse por arrancar de nuevo la tradición al conformismo que pretende avasallarla [...] El don de encender en lo pasado la chispa de la esperanza sólo le es dado al historiador perfectamente convencido de que ni siquiera los muertos estarán seguros si el enemigo vence. Y ese enemigo no ha cesado de vencer.

Walter Benjamin.

12 de octubre del año 1492, el navegante Cristóbal Colón vislumbra la consecución de sus objetivos. Ondeando en lo alto de La Santa María, La Niña y La Pinta, la bandera de la corona de Castilla con el sello de los Reyes Católicos ve concluir uno de los viajes más importantes para la historia de la humanidad. El Almirante, por fin, pisa tierra, un espacio que, a partir de ese momento, presenciará la apertura de nuevos mercados, la incorporación de nuevas áreas de explotación colonial y, por qué no, protagonizará el acto que resolverá el afán occidental de trascender en la Historia, haciendo de esa tierra desconocida un Nuevo Mundo al que civilizar.

Con el hallazgo de este espacio inédito, Colón inaugura el imaginario americano y para describirlo a sus coterráneos traza un poderoso discurso triunfalista que legitima y acomoda lo que narra a lo que esa España renacentista, que aguarda al otro lado del océano, espera ansiosa leer. América se convierte, a partir de entonces, en un libro en blanco en el que 
poder escribir una nueva historia gloriosa y espléndida, pero un libro inspirado de antemano en los dogmas, las fuentes y los modelos europeos que condicionarán en todo momento su descripción.

Desprovisto de su estatus de civilización, la estructura histórica del Nuevo Mundo se construirá a partir de la inventio del Almirante, quién nunca contemplará América para representarla, más bien proyectará en ella todo aquello que, desde antes de partir, ya sabía que iba a encontrar.

La intención de Colón al descubrir y describir las Indias no se limitó al plano material, pues se extendió a la necesidad de poseer el pensamiento de los naturales, de controlar sus hábitos y de conquistar el imaginario de todos aquellos territorios que se debían alcanzar. Como si se tratase de un libro de caballerías, la lectura de sus relatos inducía a imaginar un mundo nuevo, a avivar la imaginación para las aventuras de quiénes se interesaban por las américas y a llenar la mente de todos los que escuchaban sus historias de "relatos -aparentemente auténticos- de lugares fantásticos, de riquezas, monstruos y encantamientos» (Torre Villar, 1990, 38-39).

No es baladí que el derrame fantástico de Colón, como el de tantos otros soldados que formaron parte de las expediciones del Nuevo Mundo, coincida con el auge de la literatura de ficción en Europa. Estas novelas de aventuras que ingresaban en la Península, y que tanto alarmaban a ciertos sectores de nobles y religiosos, inyectaron este espíritu caballeresco en los protagonistas de las gestas transoceánicas y moldearon la realidad de la conquista, confiriéndole «un carácter totalmente distinto del que tuvieron empresas similares llevadas a cabo por otras naciones» (Leonard Irving, 1984: 316).

En las tierras recién descubiertas, España habría de imponer su hegemonía con el apoyo de la fe católica y el lenguaje, dos de los eslabones que protagonizarían la hagiografía de la conquista, regularizarían la conducta de los naturales y «legitimarían toda una serie de acciones sociales y culturales que iban a desarticular el equilibrio indígena» (Moreno Toscano, 1980: 330). Así, tras la exploración y explotación del continente (re)descubierto, el primer gesto de control sobre el territorio nuevo debía ser un necesario acto de nominalización, «una ceremonia inaugural de reafirmación del poder exterior que iba a convertir el territorio en América y, con el tiempo, latina» (O’Gorman, 1995:17). La recién bautizada tierra aparecía frente a los ojos de los occidentales como un espacio virgen, inocente y deseoso de ser ilustrado, hecho que determinaría el segundo episodio de dominio, el de la empresa formativa. Esta visión heroica y casi mesiánica del proceso de (trans)culturación, sustentado en la superioridad natural del hombre blanco, justificó la necesidad de occidentalizar a la sociedad indígena para lo cual fue necesario imponer las formas hispanas de comunicación, de pensamiento, de vida:

Más que hispanización fue una occidentalización, pues esta implica códigos, modelos, técnicas y políticas que rebasan los confines de la península ibérica [...] La occdidentalización no podría reducirse a los azares de la cristianización y a la imposición del sistema colonial; anima procesos más profundos y más determinantes: la evolución de la representación de la persona y de las relaciones entre los seres, la expresión y transmisión del saber, la mutación de la temporalidad y de la creencia, en fin, la redefinición de los imaginarios y de lo real en que los indios fueron destinados a expresarse y a subsistir, forzados o fascinados (Serge Gruzinski, 1991: 279-280). 
El lenguaje, la expresión y la capacidad de comunicarse, no solo actuaron como un vehículo de trasmisión de ideas y conocimientos. También, como advirtieron en otro contexto Sapir y Wharf, se convirtieron en un modelador de pensamiento y en una herramienta de control, tanto de las categorías significativas de las palabras como de los usos que de ellas se hacían (Shera, 1990: 54). La palabra hablada, escrita o impresa se insertó en el imaginario colectivo indígena como forma social de comunicación, «siendo el propio sistema social el que producía la comunicación, y esta, a su turno, la que mantenía el sistema social» (Ramírez Leyva, 2001: 4). Ante ello, las coacciones en el uso, tanto del lenguaje, como de las formas de trasmisión occidentales del saber, no solo supusieron la imposición de un sistema de comunicación diferente. También conllevaron la instauración de un sistema de conciencia que se aplicaría a todos los aspectos de la vida y que ejercería un modelo de disciplina y control que persiste hasta nuestros días. Con la llegada de Colón a las costas americanas, la cultura indígena y la vida en sí misma quedarían reducidas al sistema social de comunicación occidental, articulado como un sistema capaz de disciplinar a los individuos recién sometidos y como una forma de control sobre su vida, legitimada hasta nuestros días. "Hay cosas más importantes que tu película», sostiene Daniel, deteniendo el metraje, «el derecho a la vida».

Cochabamba, Bolivia, año 2000, Sebastián -Gael García Bernal-, como director del proyecto, y Costa -Luís Tosar-, como productor, comienzan el rodaje de una película sobre la escritura del Descubrimiento y la Conquista de América. El presupuesto es modesto y por ello el equipo escoge Bolivia y no el Caribe para rodar la consecución de la empresa interoceánica. Karra Elejalde, como Antón, será el protagonista, el Almirante llamado a normar y corregir la desviación y la herejía de Daniel -Juan Carlos Aduviri- y el resto de los naturales que asisten a la llegada de la divinidad española, ansiosos por firmar el contrato social de sometimiento.

El problema surge cuando el proceso de grabación de la película se ve interrumpido por las protestas contra la privatización del abastecimiento del agua potable municipal. Daniel, el líder indígena que en las primeras escenas del rodaje observaba atónito a un Colón ataviado con las armas del progreso y el sentido, resulta ser, a su vez, el adalid de la conocida Guerra del agua (2000). El activismo del líder que milita contra la explotación de los recursos de su territorio, contrasta con el quietismo de su personaje en la película e inaugura un espectro histórico que invita al espectador a conectar ambas formas de control y explotación social. ${ }^{1}$ También la lluvia propone, desde su inicio, un juego de paralelismos que vincula, no solo las formas de explotación material y aprovechamiento del siglo XVI con las del XXI, también la aplicación e impacto del poder y el control en todos los aspectos de la vida. Pues, si bien la empresa colombina «debía mostrar el buen ejercicio a los indios y los caminos de la buena vida» (Borges Morán, 1986: 259), ahora quedaba legitimado que las nuevas políticas imperialistas pudiesen quitársela. Así, «el control externo sobre los individuos no solo se efectuó mediante la conciencia o por la ideología, sino también en el cuerpo y con el cuerpo». La lucha por el agua y la voluntad de privatizar su uso convirtió

1 Entre los meses de enero y abril del año 2000 Cochabamba protagonizó una serie de protestas contra el golpista Hugo Banzer por sus gestiones con el consorcio empresarial extranjero conocido como Aguas del Tunari. Pronto las consecuencias del acuerdo, mediante el cual se restringía el servicio de suministro de agua, desencadenaron progresivas subidas de las tarifas del agua, que tuvieron como consecuencia la quiebra de la economía nacional. Para hacer frente a estas protestas, el gobierno declaró la ley marcial, otorgando así facultades extraordinarias a las fuerzas armadas para que sofocaran los múltiples disturbios originados por la situación de extrema pobreza que se vivió. 
el control sobre el otro que se ejercía desde los tiempos de la Conquista, en un biopoder ejercido sobre él, que ya no se conformaba con regular únicamente su sistema social y cultural, necesitaba controlar también sus formas de vida (Foucault, 1999: 245).

La estrategia metafílmica de la película dentro de la otra película es la que permite desarrollar, sin incoherencias internas, un proceso de retroalimentación en el que las historias se repiten a través de sutiles guiños. Sin embargo, este vínculo no aparece explícito, sino que se percibe, entre otros mecanismos, a partir de diferentes técnicas de representación de imagen y guion que confrontan los dos momentos históricos. En este sentido, la primera escena, brillante en términos cinematográficos, resulta clave para entenderlo: colosal cruz sobrevolando el paisaje americano. Imagen de gran plasticidad, la del poder del cristianismo atravesando el horizonte americano virgen, inexplorado y grandioso. El helicóptero como lo extraño y su distinción frente al vasto paisaje remiten al enfrentamiento de dos lugares simbólicos, significativos en la narrativa de la Conquista y en la dimensión pragmática de la obra: la civilización frente a la barbarie. La frontera entre esos dos lugares se revela como el lugar de enunciación desde el que la película narra las historias y de su continua confrontación surge el potencial crítico de esta.

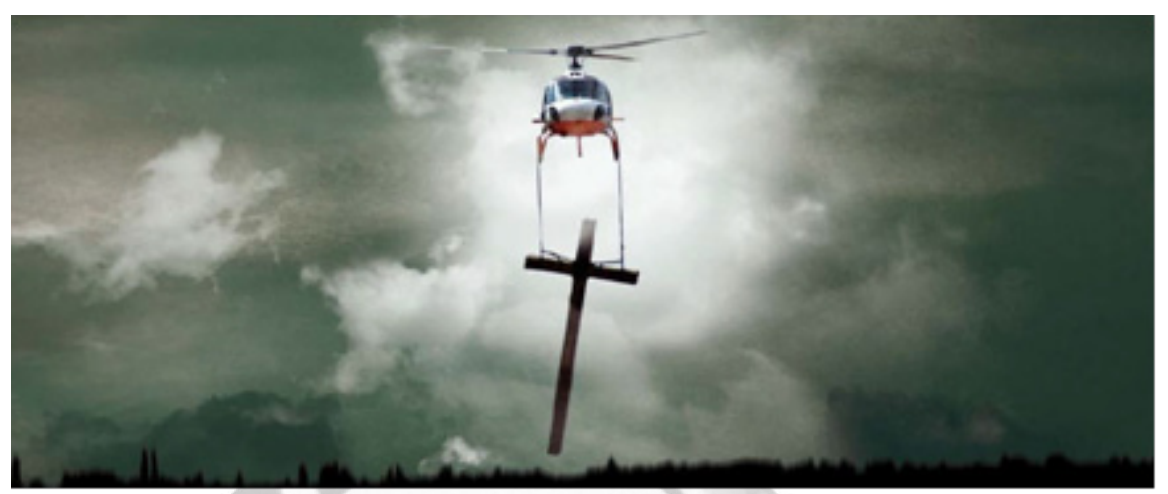

La gran cruz de madera, decorado de una de las últimas escenas, será levantada del suelo y plantada en el paisaje por varios campesinos indígenas. Con el objetivo de ahorrar costes innecesarios con la contratación de grúas y personal especializado, Costa dirigirá a los campesinos para poder colocarla. En este caso el lenguaje audiovisual privilegia un angulación de abajo a arriba, la cruz, símbolo de control, poder y grandeza corta el cielo. El plano contrapicado, junto con la insistente reiteración de estos detalles, que fusionan las temporalidades, nos recuerda que la memoria es la base constructora del relato que se repite y del discurso reflexivo que lo circunda.

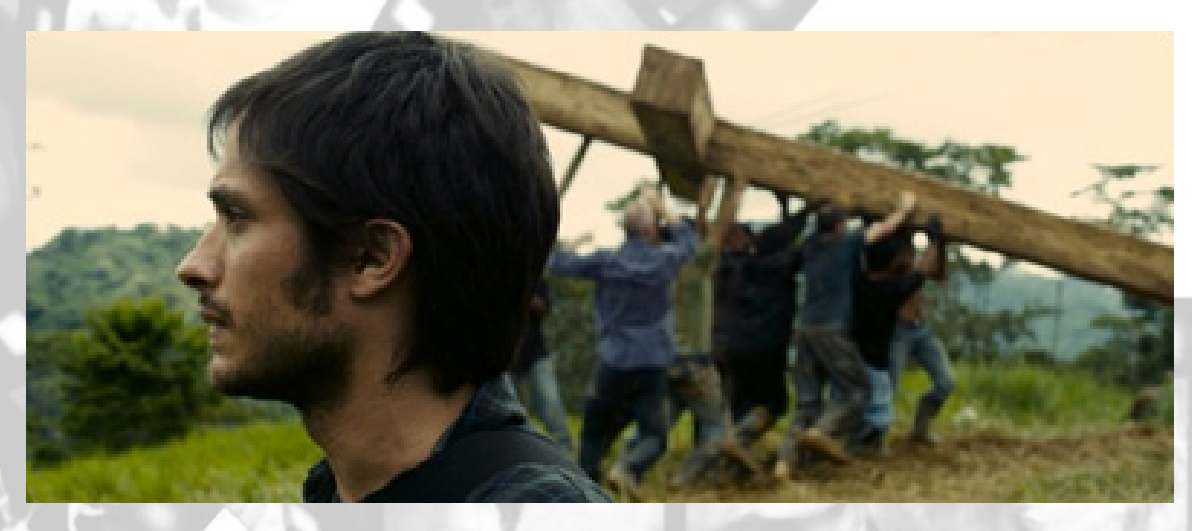




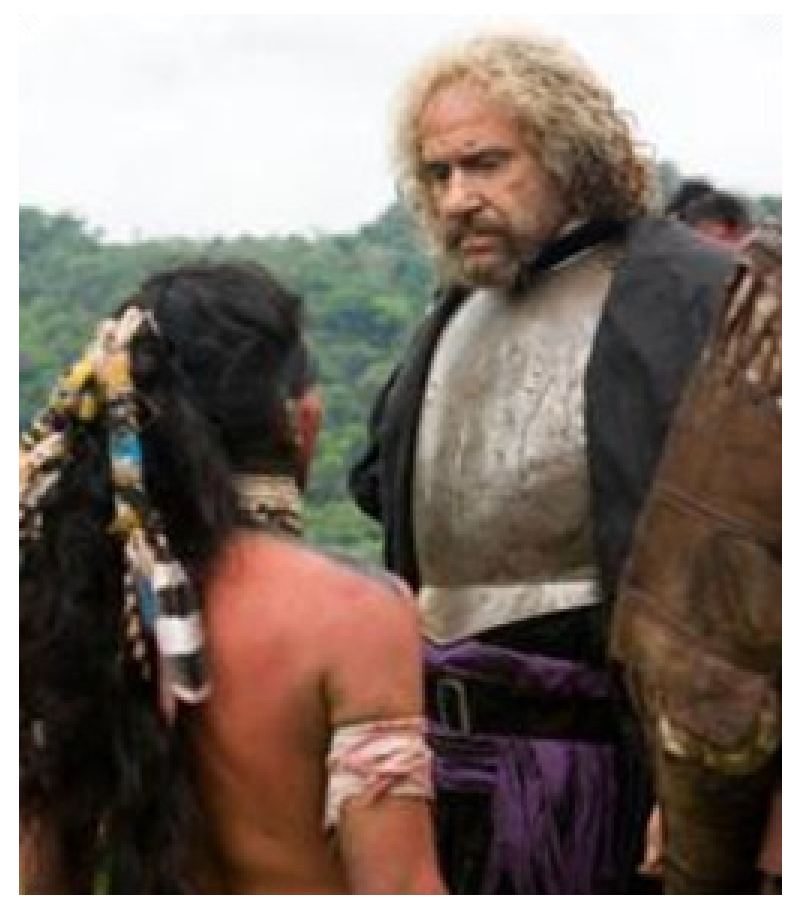

Toda la estética de la película, su tonalidad visual, su impecable factura, incide también en la representación confrontada de los personajes. En esa línea de antítesis reveladoras, hay una lectura de lo acontecido que pasa por la forma en que se construye a los protagonistas. La caracterización por contraste de los personajes, tanto a nivel discursivo como de imagen, será parte significativa de ese registro simbólico de la memoria.

Si la primera escena era crucial para entender la alegoría de los dos mundos, el primer encuentro entre Daniel y Antón, como indígena y Almirante, es también revelador. Karra Elejalde, boquiabierto ante el paisaje extraordinario que se le presenta, necesita verificar - en un escenario donde no se ve identificado con nada- lo que es, confirmando aquello que no es. El perfil de los personajes protagonistas se construye siguiendo el mismo procedimiento que el de los actores de la conquista, así el encuentro entre el colono y el indígena reproduce un reconocimiento desde la diferencia.

En el marco del rodaje, las cámaras filman planos que confrontan a los personajes en una especie de reflejo diferencial:

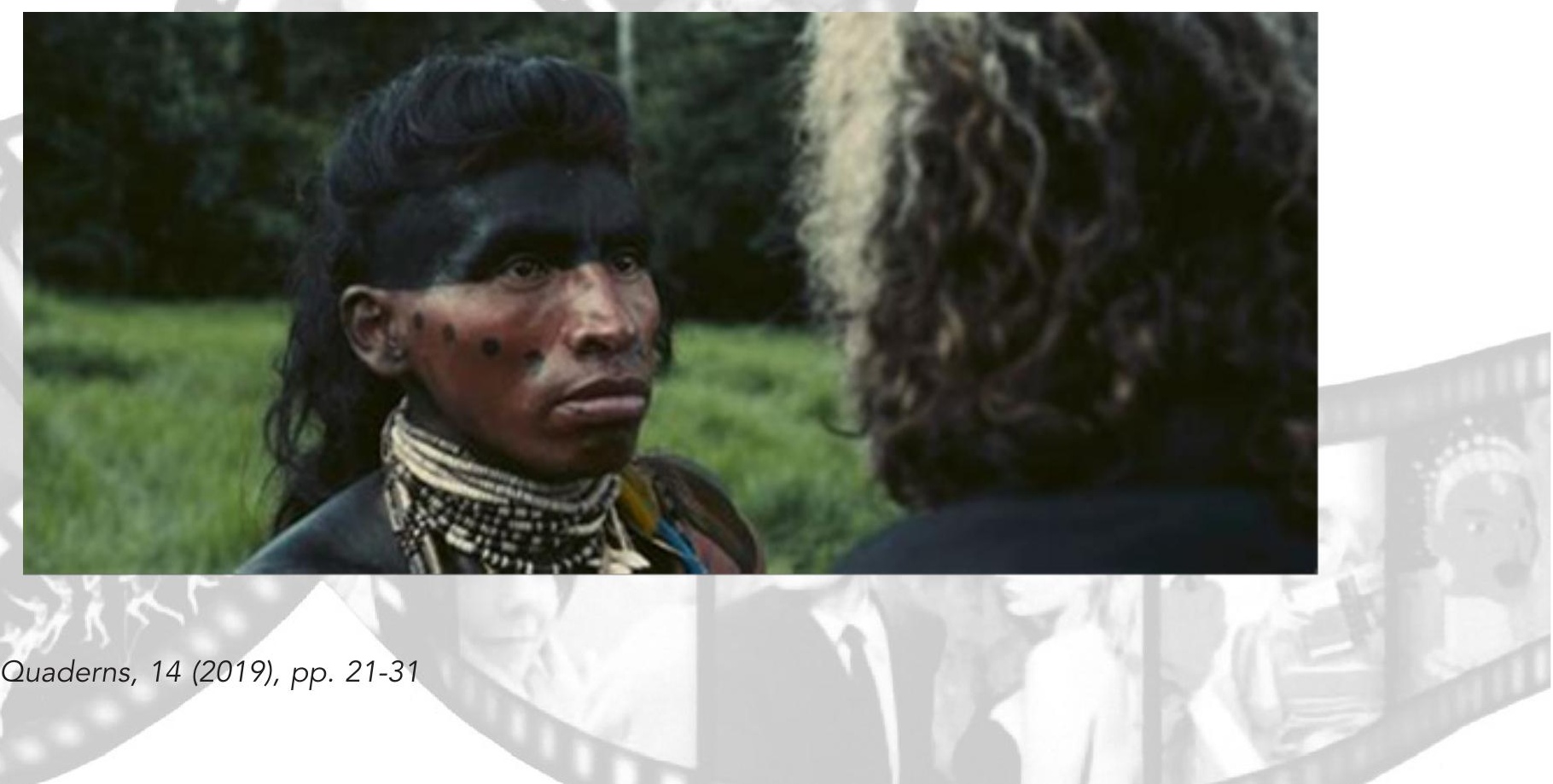


El resultado de este tipo de planos, tal como se capturan aquí, no solo logra un efecto visual de gran potencial, sino que conceptualiza lo que fue el encuentro entre los dos mundos. En su magnífico estudio sobre las relaciones entre el yo y el otro Enmanuel Levinas desgranó las dimensiones principales de la construcción de la identidad desde la figura del opuesto. Para Levinas, según se detalla en Humanism of the face, la interpretación del sujeto y del propio yo se retroalimenta, siendo, a su vez, sujeto y objeto: El otro nace del reconocimiento de nuestras carencias, pero el yo se completa mediante la formulación de ese otro. De manera que, según el filósofo, en la construcción de la subjetividad se hallaría implícita la reflexión sobre la alteridad. El sujeto, de forma individual, sería, según él, incapaz de alcanzar una imagen total de sí mismo. Al respecto, Todorov sostiene:

Nosotros nunca nos vemos a nosotros mismos como un todo; el otro es necesario para lograr, aunque sea provisionalmente, la percepción del yo, que el individuo puede alcanzar sólo parcialmente con respecto a sí mismo. Las objeciones posibles se plantean en seguida: ¿acaso en el espejo no se encuentra la visión completa del yo? ¿O, en el caso de un pintor, en un autorretrato? En los dos casos, la respuesta es: no (Todorov, 1987: 95).

En esta línea, la cercanía hacía el otro no se resolvería como necesidad de conocimiento de la alteridad, sino como una búsqueda de afirmación de lo propio. Así, el encuentro entre los dos mundos no se reduciría solo a necesidad de definir al indígena como realidad desconocida, sino que incluiría una dimensión ética de auto reconocimiento. Bollaín conoce bien todo este entramado teórico y lo incluye en el discurso cinematográfico. Así, todos los elementos favorecen un cierto ambiente visual y sonoro, desde la vestimenta, la escenografía y la iluminación hasta el registro de actuación y la música, en el que estos procedimientos de reconocimiento del yo y el otro aparecen acentuados. La identidad de los protagonistas, siguiendo el discurso colombino, se afirma cuando se asume la diferencia, en cuanto lo exótico del otro y su confinamiento al caos y a la barbarie sirven para fijar los límites del yo. La caracterización diferencial de los personajes delimita un perímetro simbólico de identidad que los protege de lo desconocido.

Todos estos elementos no son procedimientos aislados del rodaje metacinematográfico, sino que se utilizan también para capturar aquellas escenas en las que los personajes aparecen sin atrezo:

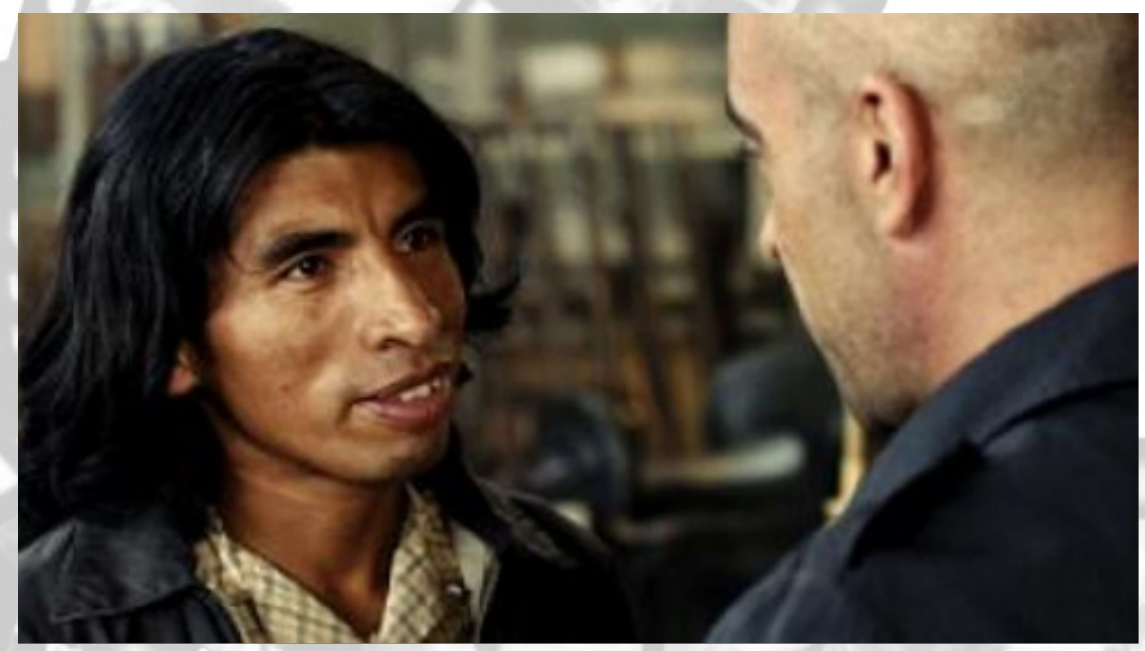


Como en la escena anterior, es precisamente cuando estos planos aparecen integrados en una sintaxis reconocible cuando ganan mayor significación, ya que abren un espacio significativo en el que el signo de reconocimiento por contraste se convierte en una estrategia de tránsito entre un relato y otro.

Además de los medios planos que singularizan a los personajes y permiten que el espectador pueda observar con todo lujo de detalles estas contraposiciones, los planos generales y los planos americanos logran otro efecto de sentido en una línea similar a la que veíamos. Si los planos individuales permiten ver a un indio privado de ley, costumbres y religión, más fruto de la imaginación que de la naturaleza, muy cercano al que Colón imaginaba en sus diarios, los planos más amplios resaltan todavía más este efecto en las imágenes grupales. La fuerza de estos planos y la extrañeza que le causan al espectador, se producen, en este caso, gracias a la potente carga significativa que condensa el conjunto de individuos, con todo ese repertorio de características estandarizadas: plumas en abundancia, pintura cuanta más mejor, gritos y desorden, toda una identificación orientada a materializar una imagen del indio excitante, provocadora, exótica y diferencial. Así, para acentuar el caos, el otro se representa como una masa homogeneizada, desposeída de todo rasgo diferencial y reducida a la animalización, la falta de civilización, al primitivismo. Una estrategia de representación que se repite en las escenas del presente, especialmente en aquellas que captan el conflicto político-social que se está viviendo. Un gesto que, sin duda, consiste en el borrado de la diferencia histórica y la disolución de los límites de poder:
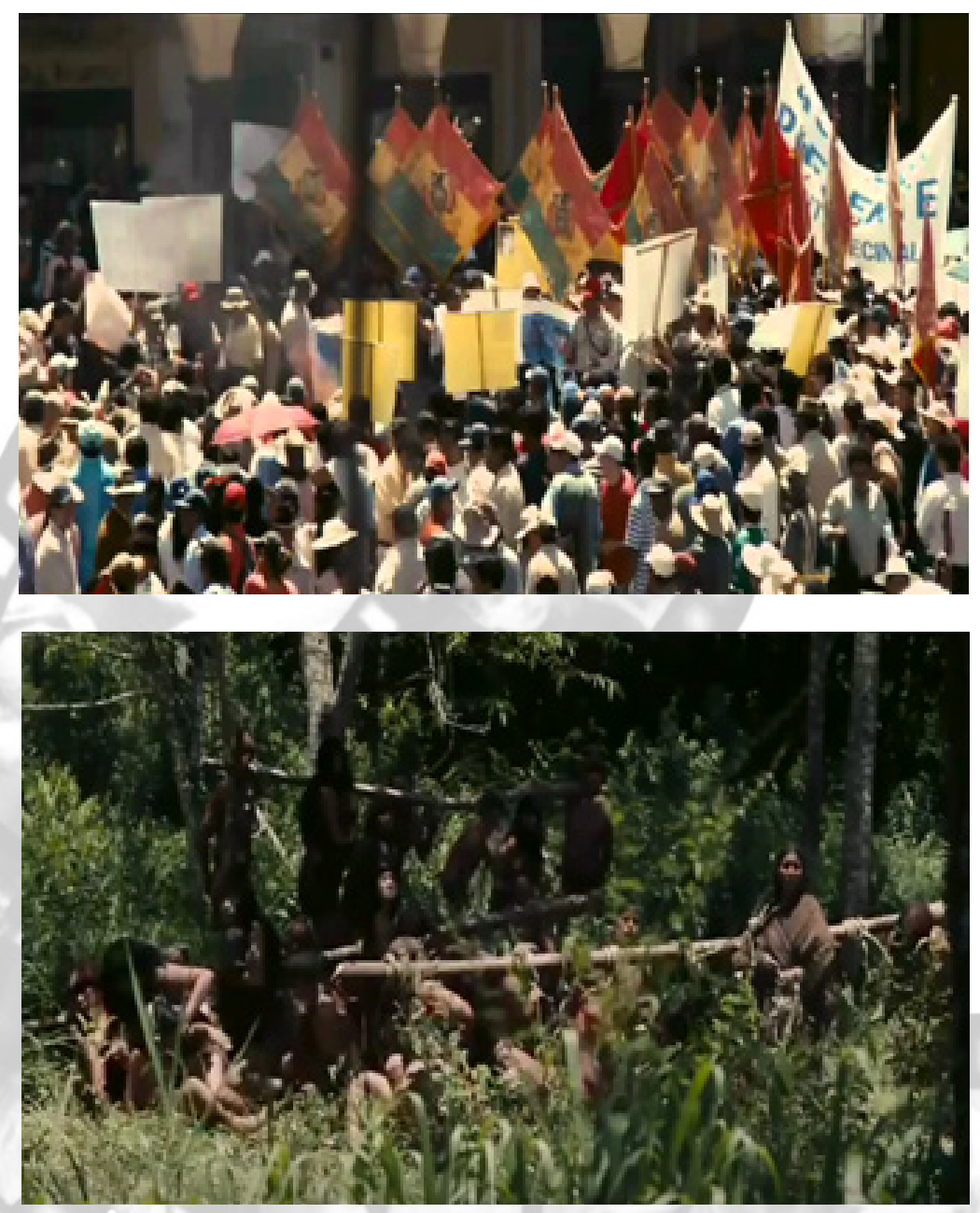

Quaderns, 14 (2019), pp. 21-31 
Y, en la misma línea, el lenguaje será también un mecanismo constitutivo de nuevas conexiones. Si el acto discursivo es, en el relato colombino, una forma de poder que marca la diferencia categórica entre el sujeto civilizado y la barbarie indígena, también en el otro relato del presente el lenguaje aparece como mecanismo de privilegio:

Mientras Costa le pide a Daniel que por tres semanas se mantenga al margen del conflicto político-social en el que está inmerso la conversación es interrumpida por el estadounidense que financia el proyecto. Pensando que Daniel no sabe inglés, el director ríe al teléfono, diciendo que paga dos dólares al día a los extras, implicando que sabe que es una pequeña suma por todo lo que hacen. Cuando Costa pretende retomar la conversación, Daniel le sorprende informándole que ha entendido toda la conversación: "¿dos putos dólares no? Y ellos tan contentos." Enfadado, abandona el lugar (Isasi, 2013: 3-4).

En este caso, la atención del espectador se focaliza en la noción cultural. El desconocimiento del lenguaje sitúa a los actores indígenas en una posición de subordinación y marginalidad y así lo confirma la reacción de Daniel, quién descubre el engaño. La conexión con el relato de la conquista es fácilmente identificable: el lenguaje, sea el español o el inglés, forma parte de un ritual de poder que privilegia el control sobre el otro. Si el juego de intereses ha cambiado, el reparto de papeles continúa siendo el mismo y el juego de semejanzas refuerza esta dicotomía, que sacude conciencias y problematiza los límites de ese pasado. En este sentido, todas estas tretas de representación logran que ambos momentos históricos entablen una dialéctica que concilia peligrosas semejanzas y que, trivializando el paso del tiempo, subraya la presencia de una jerarquía externa que, todavía hoy, continúa ejerciendo una forma de control sobre la vida de los otros a través de las mecanismos de poder legitimados.

\section{A MODO DE CIERRE:}

La película articula paradigmas de comprensión que cruzan los dos planos históricosociales en un proceso de reconstrucción de la memoria que consiste en dar carta de legitimidad a nuevas lecturas del pasado. El estudio de las estrategias fílmicas de representación permite comprobar de qué manera la película consagra una mirada que abdica de su capacidad de analizar el presente descausalizándolo y que, por el contrario, halla su potencial crítico en el hecho de abordar un conflicto reciente conectándolo con ciertas referencias históricas.

De esta manera, el paralelismo se constituye como eje vertebrador del relato y el juego de intereses que caracterizó la conquista se constata, nuevamente, en la lucha actual. La fotografía del espacio y el tratado de la imagen desdibujan la frontera entre la ficción y la metaficción y hacen que el salto abrupto de un tiempo a otro desaparezca. Las riquezas del continente americano, que promovieron la conquista, dominación y explotación de sus tierras resuenan, por una parte, en la actuación del equipo de rodaje que escoge Bolivia y no el Caribe para filmar la película por motivos económicos. Por otra, en la de la multinacional capaz de privar a la sociedad de un bien básico como es el agua, desencadenando así una situación de caos, quiebra económica y precariedad. 
Ambas formas de poder y dominación se fundamentan, no solo en el dominio del territorio que se ocupa, sino también en la intervención y regulación de las formas de vida de quiénes habitan en ese espacio. Así, la concepción del indígena que vive en esas tierras nace de una visión paternalista, infravalorada, esquemática y simplista y atiende siempre a legitimar el provecho que de él se puede extraer.

En consecuencia, todos estos mecanismos intertextuales, que ponen a dialogar el relato histórico con el conflicto social, cumplen una función primordial: la de abrir un espacio representacional en el que, más allá de lo explícito, los signos velados proyecten un peligroso juego de semejanzas, basado en la repetición de pautas de dominación y la reproducción de actitudes de control frente a un otro que sigue sometido a un enemigo que no ha cesado de vencer.

\section{BIBLIOGRAFÍA CITADA}

ARTEAGA (2007): Las relaciones de poder, Madrid, Alianza.

APPIAH, Kwama Anthony (2011): La ética de la identidad, Buenos Aires, Katz Editores.

Ballesteros Beretta, A. (1945): Cristóbal Colón y el descubrimiento de América, en Historia de América y de los pueblos americanos, vols. IV y V, Barcelona, Paidós.

BARTRA, Roger (1996): El salvaje en el espejo, Barcelona, Destino.

BAUDRILLARD, Jean (2008): La precisión de los simulacros, Barcelona, Kairós.

- (2002): El asesinato de lo real, Buenos Aires, Taurus.

BernARD, C. y Serge Grusinki (1996): Historia del Nuevo Mundo. México, Editorial Guadalupe. BEUCHOT, Mauricio, Estudios de historia y filosofía en el México colonial, México, UNAM, 1991.

BOURDIEU, Pierre (1997): Razones prácticas. Sobre la teoría de la acción, Barcelona, Anagrama. CHANG RODRÍGUEZ, Raquel (1959): «Violencia y subversión en la prosa colonial hispanoamericana siglos XVI y XVII», Revista Iberoamericana, 4024, pp. 130-131.

COLÓn, Cristóbal (2002): Diario de a bordo, Madrid, Alianza.

CHARTIER, Roger (1995): Sociedad y escritura en la Edad Moderna: la cultura como apropiación, México, Instituto Mora.

DUSSEL, Enrique (1992): 1492, El encubrimiento del otro, México, Editorial Guadalupe.

ESPÓSITO, Roberto (2009), Tercera persona, política de la vida y filosofía de lo impersonal, Buenos Aires, Amorrortu.

FOUCAULT, Michel (1982), El orden del discurso, México, Ediciones Populares.

GARDUÑO, Everardo (2007): La conquista de América, el problema del otro, México, Editorial Guadalupe.

GonZalvo, Pilar (1985): El humanismo y la educación en la Nueva España, México, SEP/ Dirección General de Publicaciones- El Caballito.

GRUZINSKI, Serge (1991): La colonización de lo imaginario: sociedades indígenas y occidentalización en el México español: siglos XVI-XVIII, México, FCE.

IRVING, Leonard (1996): Los libros del conquistador, México, FCE.

MORENO TOSCANO, Alejandra (1980), "El siglo de la Conquista», en Historia general de México, México, El Colegio de México, vol. 2.

O'GORMAN, Edmundo (1995): La invención de América. El universalismo de la cultura de Occidente, México, Fondo de cultura económica. 
O'GORMAN, Edmundo (1996): La idea del descubrimiento de América. Historia de esa interpretación y crítica de sus fundamentos, México, Imprenta universitaria.

SHERA Jesse (1990): Los fundamentos de la educación bibliotecológica, México, UNAM.

TODOROV, Tzvetan (1987): La conquista de América. El problema del otro, México, Editorial Guadalupe.

TORRE VILLAR, Ernesto (1990), Breve historia del libro en México, México, UNAM.

- (2004): El Nuevo Mundo, México, UNAM.

TRAVERSO, E (2007): Historia y memoria, notas sobre un debate, Buenos Aires, Paidós.

UGARTE PÉREZ, Javier (2006): «Biopolítica. Un análisis de la cuestión», Claves de Razón Práctica, n 196, pp. 76-82. 